\title{
A survey: Knowledge about breast cancer and health beliefs towards screening practice among menopausal and postmenopausal women
}

\author{
Wong MF Florence \\ School of Nursing \\ Tung Wah College \\ Hong Kong \\ florencewong@twc.edu.hk
}

\author{
Cheng LS Winnie \\ School of Nursing \\ Tung Wah College \\ Hong Kong \\ winniecheng@twc.edu.hk
}

\begin{abstract}
Breast cancer is a major health problem with high mortality in women worldwide and has become the third most prevalent disease among women in Hong Kong. Knowledge about breast cancer is closely related to health beliefs towards screening practices for breast cancer. This study examined knowledge about breast cancer and breast cancer screening (BCS) beliefs among menopausal and postmenopausal women. A total of 213 eligible women, mostly aged 55 to 60 , who were housewives or retired and were educated at secondary school level or above, were selected. A survey using the Chinese Breast Cancer Screening Beliefs (CBCSB) questionnaire was conducted. The results revealed that menopausal and postmenopausal women had better health beliefs towards breast cancer screening practices. Education was found to be positively associated with attitudes of BCS health beliefs. It indicates that education can affect attitudes towards breast cancer screening practice. Most of the women presented inadequate knowledge and they wished to receive more information about breast cancer although they were well-educated. It is important to note that knowledge about breast cancer cannot be effectively delivered to the at-risk women. In addition, menopausal and postmenopausal women can be more likely to seek more information about the effectiveness and side effects of the medication for breast cancer. Therefore, treatment about effectiveness, side effects, and prices ought to be included in current educational programs and healthcare services in the promotion schemes. Healthcare professionals should also pay more attention to better BCS practices in community-based educational programs with information on preventive measures for breast cancer to menopausal and postmenopausal women, particularly to those in lower socioeconomic classes.
\end{abstract}

Keywords-breast cancer; screening beliefs; knowledge; menopause; postmenopause

\section{INTRODUCTION}

Breast cancer has become one of the most concerned health problems in women, particularly in those who are at the menopausal and postmenopausal stage, in both developed and developing countries (World Health Organization [WHO] 2016). More than 200,000 invasive breast cancer types were newly diagnosed and the disease has become a major leading cause of death in the US (Siegel et al., 2016). Since 1989, mortality rate of breast cancer has been remarkably reduced due to improved medical technology and lifestyles (Breastcancer.org, 2016). In Hong Kong, breast cancer has become the third killer, surpassing lung cancer since the $1990 \mathrm{~s}$ (Center for Health Protection [CHP], 2013), and was accountable for $24.1 \%$ of all new cancers in women in 2010 and $10.3 \%$ of all cancer deaths among women in 2008 (Hospital Authority [HA], 2016). Of considering age prevalent group, Hong Kong Chinese women aged 50 or older are at higher risk group for breast cancer (Leung, et al., 2002; Wong, et al., 2015).

Breast cancer screening (BCS) is a useful tool for early detection of breast cancer (Yan, 2009). This practice includes breast self-examination (BSE), clinical breast examination (CBE), and mammograms. Cultural factor plays an important role influencing perceptions and health beliefs of breast cancer practice (Kwok \& Fong, 2014). Evidence showed that BSC practice was low in Asian countries such as Malaysia and Taiwan (Parsa, et al., 2008; Wang, et al., 2014). This practice is uncommon in Asian women (McCracken et al., 2007). Among three BSC practices, only $7.8 \%$ performed all of them (Kim, et al., 2011). Less than $40 \%$ of Asian women performed regular BCS (Gomez, et al., 2007; Parsa, et al., 2008; Wang, et al., 2014; Yan, 2009). It implies that Asian women are most likely unaware of breast cancer risks and its preventive practice (Chua, et al., 2005).

A recent study (Cheng \& Wong, 2016) reported that most of the Chinese women who were at pre-menopausal and postmenopausal stages (from 40 years old and older) had misconceptions about breast cancer risks. It is important to note that Chinese women may be indifferent and disregard breast cancer screening and preventive measures (Chua, et al., 2005). Therefore, this study aimed to examine knowledge about breast cancer and breast cancer screening practice among menopausal and postmenopausal Chinese women. The findings can provide direction towards BCS preventive measures and educational health promotions to improve the awareness of breast cancer and meet the needs of menopausal and postmenopausal women who are at risk of breast cancer. 


\section{METHODS}

\section{A. Design and sampling}

A cross-sectional survey with a convenience sample was conducted from March to April 2013. Sample size was estimated using the Epi-Info version 7 based on the number of breast cancer cases in Hong Kong in 2013, which was 3,524 (Hong Kong Breast Cancer Registry, 2013). A sample of 213 women was required to reach a desired width of a $95 \%$ confidence interval with $7 \%$ confidence limits. Women aged 40 or older without any mental health problems were invited to participate in the study. The study was carried out at a community centre in one of the urban districts in Hong Kong.

\section{B. Data collection}

A set of questions was developed by the researchers based on previous studies and professional experience to assess knowledge on the risks of breast cancer. Those questions were validated by a gynecologist. All eligible women were asked to participate in the study and sign an informed consent after the study information was given. A survey including a set of questions together with demographic information and a modified Chinese Breast Cancer Screening Belief Screening (CBCSB) questionnaire were completed through face-to-face interview. The interview took about 20 minutes.

The modified CBCSB (Fong, et al., 2012) consists of 11 items with three domains: attitudes towards general health check-ups (4 items); knowledge and perceptions about breast cancer (4 items); and barriers to mammographic screening (3 items). All items were rated using a 5-point Likert scale ranging from 1 (strongly agree) to 5 (strongly disagree). The lower score indicates the lowest attitude, least knowledge or greatest barrier and vice versa. The total scores of each domain were calculated following the formula (total score - minimum total)/(maximum total - minimum total). The Cronbach's alpha of the overall modified CBCSB was 0.79 and each domain was $0.71,0.75$, and 0.82 , respectively in this study.

\section{ETHICAL CONSIDERATIONS}

The study was approved by the School Research Committee of the educational institution. All participants were assured that they could withdraw from the study without consequences at any time. All information was anonymous to protect personal confidentiality and only used for research purpose.

\section{DATA ANALYSIS}

Data were analyzed using the IBM SPSS v20.0 (SPSS Inc., Chicago, IL, USA). Descriptive statistics were used to summarize and analyze the students' demographics and the attitudinal domains of the CBCSB. Pearson's coefficient was used to examine the relationships between variables. The level of significance was set at 0.05 for all statistical tests.

\section{RESULTS}

\section{Demographic charcteristics}

Of a total of 213 eligible women, none of them was diagnosed with breast cancer although $7 \%$ reported a family history of breast cancer. Most of them were aged 50 or older
(74.2\%). More than $80 \%(n=173)$ of the participants were married and had children. There were $132(62.0 \%)$ attained secondary or higher education. However, only $30.5 \%(n=65)$ were employed and about half of them were housewives or retired. The demographic characteristics are showed in Table 1.

TABLE I. Demographic characteristics

\begin{tabular}{|c|c|c|}
\hline Variables & Number & Percentage \\
\hline Age & & \\
\hline$<50$ & 55 & 25.8 \\
\hline $50-60$ & 100 & 46.0 \\
\hline $61-80$ & 48 & 22.6 \\
\hline$>80$ & 10 & 4.7 \\
\hline Marital status & & \\
\hline Single & 40 & 18.8 \\
\hline Married & 173 & 81.2 \\
\hline Educational level & & \\
\hline Uneducated/Primary school & 81 & 38.0 \\
\hline Secondary school & 96 & 45.1 \\
\hline Tertiary or above & 36 & 16.9 \\
\hline Occupation & & \\
\hline Unemployed & 106 & 69.5 \\
\hline Employed & 65 & 30.5 \\
\hline
\end{tabular}

\section{Knowledge about breast cancer and its risk}

Of 213 women, about $40 \% \quad(n=86)$ had sought medical advice for breast mammography in the past one year. More than half of the women $(66.7 \%)$ expressed they were worried about having breast cancer after menopause. However, regarding knowledge about breast cancer, most of the women $(85.9 \%)$ reported that they had insufficient to average knowledge about breast cancer. Regarding the risks of breast cancer and preventive medication, misconception about risks of breast cancer was found and more than half ( $60 \%)$ hoped to have preventive medication for breast cancer and wanted to receive more information about it. Most of them were concerned about effectiveness, side effects, and price of the medication for breast cancer. The details of knowledge about breast cancer and its risks are shown in Table II.

TABLE II. Knowledge about breast cancer, its risks, and concerns about preventive medications

\begin{tabular}{|l|c|c|c|}
\hline & Mean (SD) & Yes (\%) & No (\%) \\
\hline $\begin{array}{l}\text { Have sought medical } \\
\text { consultation for breast } \\
\text { checkup in the past one } \\
\text { year }\end{array}$ & $1.63(0.56)$ & $86(40.4)$ & $127(59.7)$ \\
\hline $\begin{array}{l}\text { Worry about having } \\
\text { breast cancer }\end{array}$ & $1.52(0.50)$ & $142(66.7)$ & $71(33.3)$ \\
\hline $\begin{array}{l}\text { Adequacy of knowledge } \\
\text { about breast cancer }\end{array}$ & $2.33(0.71)$ & $30(14.1)$ & $183(85.9)$ \\
\hline $\begin{array}{l}\text { Risks associated with } \\
\text { breast cancer }\end{array}$ & Mean (SD) & Agree (\%) & Disagree (\%) \\
\hline $\begin{array}{l}\text { Had undergone breast } \\
\text { surgery }\end{array}$ & $2.03(0.75)$ & $56(26.3)$ & $157(73.7)$ \\
\hline $\begin{array}{l}\text { Using breast } \\
\text { enhancement cream }\end{array}$ & $2.15(0.75)$ & $59(27.7)$ & $154(72.3)$ \\
\hline $\begin{array}{l}\text { Wearing brassière with } \\
\text { wire }\end{array}$ & $2.47(0.90)$ & $30(14.1)$ & $183(85.9)$ \\
\hline Using anti-deodorant & $2.43(0.95)$ & $43(20.2)$ & $170(79.8)$ \\
\hline Using perfume & $2.44(0.81)$ & $23(10.8)$ & $190(89.2)$ \\
\hline $\begin{array}{l}\text { Taking oral } \\
\text { contraceptives }\end{array}$ & $2.25(1.15)$ & $84(39.4)$ & $129(60.6)$ \\
\hline Breastfeeding & $2.30(0.62)$ & $2(0.9)$ & $211(99.1)$ \\
\hline
\end{tabular}




\begin{tabular}{|l|c|c|c|}
\hline Stress & $1.92(1.10)$ & $110(51.6)$ & $103(48.4))$ \\
\hline Regular exercise & $2.13(0.52)$ & $7(3.3)$ & $206(96.7)$ \\
\hline $\begin{array}{l}\text { Concerns about } \\
\text { preventive medications } \\
\text { for breast cancer }\end{array}$ & \multicolumn{3}{|l|}{} \\
\hline Effectiveness & $3.36(1.48)$ & $154(72.3)$ & $59(27.7)$ \\
\hline Side effects & $3.60(0.77)$ & $172(80.7)$ & $41(19.3)$ \\
\hline Price & $2.98(1.53)$ & $106(49.8)$ & $107(50.2)$ \\
\hline
\end{tabular}

The knowledge and perceptions about breast cancer showed a higher mean $(14.19 \pm 3.81)$ than attitudes of health beliefs towards general health check-ups and barriers to mammographic screening $(11.51 \pm 3.74$ and $11.47 \pm 3.14$ respectively). The total scores of attitudes towards general health check-ups, knowledge and perceptions about breast cancer and barriers to mammographic screening were 148.69, 183.31, and 197.58 respectively. Table III illustrates the domains of breast cancer screening beliefs.

TABLE III. Domains of breast cancer screening belief.

\begin{tabular}{|l|c|c|}
\hline $\begin{array}{l}\text { Domains of health beliefs on } \\
\text { breast cancer }\end{array}$ & $\underline{\text { Mean (SD) }}$ & $\begin{array}{c}\text { Total score } \\
\frac{\text { (ranging from }}{\mathbf{5 3 . 0 - 2 6 6 . 0 )}}\end{array}$ \\
\hline Total Attitude & $11.51(3.74)$ & 148.69 \\
\hline Total Knowledge & $14.19(3.81)$ & 183.31 \\
\hline Total Barrier & $11.47(3.14)$ & 197.58 \\
\hline
\end{tabular}

\section{E. Correlations between education and three domains of breast cancer screening beliefs}

The results showed that education had positive correlations with attitudes of breast cancer screening belief: attitudes towards general health check-ups $(\mathrm{r}=0.220, \mathrm{p}=0.002)$, knowledge and perceptions about breast cancer $(\mathrm{r}=0.122$, $\mathrm{p}=0.091)$, and barriers to mammographic screening $(\mathrm{r}=0.135$, $\mathrm{p}=0.062$ ). Table IV shows the correlations between education and domains of breast cancer screening beliefs.

TABLE IV. Correlations between education and domains of breast cancer screening beliefs

\begin{tabular}{|l|c|c|}
\hline & \multicolumn{2}{|c|}{ Education } \\
\hline & Pearson's correlation & p-value \\
\hline Total Attitude & 0.220 & 0.002 \\
\hline Total Knowledge & 0.122 & 0.091 \\
\hline Total Barrier & 0.135 & 0.062 \\
\hline
\end{tabular}

\section{DISCUSSION}

Our study revealed that all women were at menopausal and postmenopausal stages in which they are at high risk of breast cancer (Leung, et al., 2002; Wong, et al., 2015). Therefore, they are the target group for education on breast cancer including preventive measures and treatment. However, those women reported themselves having inadequate knowledge about breast cancer. It can be explained that those women at risk of breast cancer will not seek medical advice as they perceive themselves at lower risk and present ignorance of severity and susceptibility arising from breast cancer although they have been well-educated. It also indicates that health education on this area is not adequately able to reach these target women (Yan, 2009; Wang et al., 2014). Although evidence showed that breast cancer has higher mortality and is more prevalent in women who are at menopausal and postmenopausal stages, it is important to establish effective strategies of health promotion to increase their awareness of breast care (Sim, et al., 2009). Besides, most of the menopausal and postmenopausal women are housewives and retired. The strategies should be diverse, aiming to draw their attention and improve their awareness of breast wellness.

In our study, menopausal and postmenopausal women reported better knowledge of health beliefs towards BCS practice and fewer barriers to have mammographic screening. It indicates that women who are at risk of breast cancer have better knowledge and perception about breast cancer and they tend to be more positive about mammographic screening. It can be due to the fact that well-educated women are more likely to have more understanding about mammographic screening. Therefore, those women can accept the mammographic screening more easily.

However, due to inadequate knowledge about breast cancer, those women do not have good attitudes towards breast cancer screening practice and they will not be aware of the importance of BCS practice (Sim et al., 2009). It can also explain why those women reflected that they were worried about breast cancer and would like to have more information about breast cancer and its preventive measures. The result reported that knowledge can affect attitudes towards BCS practice. Therefore, most of the women do not seek regular medical consultation for breast check-up because they do not have sufficient knowledge. It indicates that adequate knowledge about breast cancer can increase awareness and willingness to have early detection of breast cancer and regular medical consultation for better breast wellness.

In addition, education was found to have positive association with attitudes of breast cancer screening practice only. It indicates that women who have received education are more likely to be more willing to seek medical advice and have better attitudes towards breast cancer checkups. It is important to note that women who receive better knowledge about breast cancer are able to perform better breast cancer screening practice in order to early detect and perform preventive measures for breast problems once they are appropriately educated. Inadequate knowledge about breast cancer is the major obstacle towards BCS practice and related preventive measures (Al-Sakkaf \& Basaleem 2016). Therefore, breast cancer educational programs are necessarily developed using a community-based approach to promote breast wellness and screening practices (Chan, et al., 2007). Therefore, education about breast cancer is necessarily delivered to those at-risk women even with higher education. A study reported that menopausal and menopausal women in low socio-economic classes might need further education provided by healthcare professionals on breast cancer and its preventive measures in order to increase their awareness of breast wellness (Cheng \& Wong, 2016). It indicates that healthcare professionals should pay more attention to the women who are at both higher and lower socioeconomic classes. Strategies and educational health policies must be developed to reach those at-risk women with socioeconomic needs. 
Moreover, the menopausal and postmenopausal women in our study also presented their concerns on effectiveness, side effects, and prices of preventive medications for breast cancer. It is important for the government to develop new policies and promotion schemes with adequate support, such as financial and resource support, for at-risk women to easily access such healthcare services for their positive and proactive breast wellness.

There were some limitations to this present study. It was the self-report survey that can overreport or underreport the findings on health beliefs of breast cancer screening practice. However, this study findings can direct future interventional studies in menopausal and postmenopausal between Chinese women and elsewhere.

\section{CONCLUSION}

The present study has revealed that the menopausal and postmenopausal women perceived better health beliefs towards breast cancer screening practice. Education was also found to be positively associated with attitudes of BCS beliefs. However, those at-risk women reported themselves with inadequate knowledge about breast cancer although they were well-educated. It is important to note that current education is probably not able to reach this specific population. It results in inadequate understanding about BCS practice. Therefore, it is important that healthcare promotion schemes should be developed to improve awareness towards breast cancer, its risks and preventive measures in order to promote better breast wellness and care among this specific female population. Adequate support must be given to those at-risk women, particularly those in lower socioeconomic classes, to receive adequate beneficial healthcare support.

\section{ACKNOWLEDGMENT}

We acknowledge that this study was supported with fund by Takeda Pharmaceuticals (Hong Kong) Limited.

\section{REFERENCES}

[1] Abbaszadeh A, Haghdoost A, Taebi M, Kohan S. The relationship between women's health beliefs and their participation in screening mammography. Asian Pac J Cancer Prev. 2007; 8(4): 471-475.

[2] Al-Sakkaf K.A., BasLEEM, h.o. Breast cancer knowledge, perception and breast self-examination practices among Yemeni women: an application of the Health Belief Model. Asian Pac J Cancer Prev, 2016, 17 (3): 1463-1467.

[3] Breastcancer.org. U.S. Breast cancer statistics. Retrieved 18 October 2016 from http://www.breastcancer.org/symptoms/understand_bc/statistics.

[4] Center for Health Protection (CHP). Breast cancer. Retrieved from http://www.chp.gov.hk/en/content/9/25/53.html.

[5] Chan SSC, Chow DMK, Loh EKY, Wong DCN, Cheng KKF, Fung WYC, Cheung PSY. Using a community-based outreach program to improve breast health awareness among women in Hong Kong. Public Health Nurs. 2007; 24: 265-273.
[6] Cheng LSW, Wong MFF. A survey of the perceived risks of breast cancer in menopausal and postmenopausal women in Hong Kong. GSTF JNHC. 2016; 4(1). doi: 10.5176/2251-3833_GHC16.60.

[7] Chua MST, Mok TSK, Kwan WH, Yeo W, Zee B. Knowledge, perceptions and attitudes of Hong Kong Chinese women on screening mammography and early breast cancer management. Breast J. 2005; 11 : 52-56.

[8] Fong DYT, Kwok C, White K. Psychometric properties of the Chinese Breast Cancer Screening Beliefs questionnaire. Eur J Oncol Nurs. 2012; 16(5): 505-511. doi:10.1016/j.ejon.2012.01.001

[9] Gomez SL, Tan S, Keegan THM, Clarke CA. Disparities in mammographic screening for Asian women in California: a crosssectional analysis to identify meaningful groups for targeted intervention. BMC Cancer. 2007; 7(1): 1-12. doi:10.1186/1471-2407-7201.

[10] Hong Kong Breast Cancer Foundation (2013). Hong Kong Breast Cancer Reistry, report no. 5. Retreived from http://www.hkbcf.org/data.php?aid=113\&did=177\&lang=eng

[11] Hospital Authority (HA). Breast cancer. Retrieved from http://www21.ha.org.hk/smartpatient/en/cancerin_focus/details.html?id= 93.

[12] Hospital Authority (HA). Overview of 2013 HK cancer statistics. Retrieved from https://www3.ha.org.hk/cancereg/Summary\%20of\%20CanStat\%202013. pdf.

[13] Kim JI, Oh KO, Li CY, Min HS, Chang ES, Song R. Breast cancer screening practice and health-promoting behavior among Chinese Women. Asian Nurs Res. 2011; 5(3): 157-163. doi:http://dx.doi.org/10.1016/j.anr.2011.09.005.

[14] Leung GM, Lam TH, Thach TQ, Hedley AJ. Will screening mammography in the east do more harm than good? Am J Public Health. 2002; 92(11): 1841-1846.

[15] McCracken M, Olsen M, Chen MS, Jemal A, Thun M, Cokkinides V, Deapen D, Ward E. Cancer incidence, mortality, and associated risk factors among Asian Americans of Chinese, Filipino, Vietnamese, Korean, and Japanese Ethnicities. CA Cancer J Clin. 2007; 57(4): 190205.

[16] Okobia MN, Bunker CH, Okonofua FE, Osime U. Knowledge, attitude and practice of Nigerian women towards breast cancer: A cross-sectional study. World J Surg Oncol. 2006; 4:11. doi:10.1186/1477-7819-4-11.

[17] Parsa P, Kandiah M, Mohd Nasir MT, Hejar AR, Nor Afiah MZ. Reliability and validity of Champion's Health Belief Model Scale for breast cancer screening among Malaysian women. Singapore Med J. 2008; 49(11): 897-903.

[18] Siegel RL, Miller KD, Jemal A. Cancer statistics, 2016. CA: A Cancer J Clin. 2016; 66(1): 7-30. doi:10.3322/caac.21332.

[19] Sim HL, Seah M, Tan SM. Breast cancer knowledge and screening practices: a survey of 1,000 Asian women. Singapore Med J. 2009; 50(2): 132-138.

[20] Wang WL, Hsu SD, Wang JH, Huang LC, Hsu WL. Survey of breast cancer mammography screening behaviors in Eastern Taiwan based on a health belief model. The Kaohsiung J Med Sci. 2014; 30(8): 422-427. doi:http://dx.doi.org/10.1016/j.kjms.2014.04.007.

[21] Wong IO, Schooling CM, Cowling BJ, Leung GM. Breast cancer incidence and mortality in a transitioning Chinese population: current and future trends. Brit J Cancer. 2015; 112(1): 167-170. http://doi.org/10.1038/bjc.2014.532.

[22] World Health Organization (WHO). Breast cancer awareness month in October. Retrieved from http://www.who.int/cancer/events/breast_cancer_month/en/

[23] Yan YY. Breast cancer: knowledge and perceptions of Chinese women in Hong Kong. Global J Health Sci. 2009; 1(2): 97-105. 